\title{
Mode of Action
}

National Cancer Institute

\section{Source}

National Cancer Institute. Mode of Action. NCI Thesaurus. Code C146999.

The mechanism by which a pharmacologically active substance produces an effect on the cellular level of a living org anism or in a biochemical system. 